\section{ECCOMAS}

Proceedia
COMPDYN 2019

$7^{\text {th }}$ ECCOMAS Thematic Conference on Computational Methods in Structural Dynamics and Earthquake Engineering M. Papadrakakis, M. Fragiadakis (eds.) Crete, Greece, 24-26 June 2019

\title{
A COST-EFFECTIVE RETROFITTING TECHNIQUE FOR URM BUILDINGS BASED ON STEEL ENCIRCLEMENTS IN OPENINGS: A CASE STUDY
}

\author{
M.L. Segovia-Verjel ${ }^{1}$, E. Justo-Moscardó ${ }^{1}$, A. Morales-Esteban ${ }^{1}$, M.V. Requena-García- \\ Cruz $^{1}$, E. Romero-Sánchez ${ }^{1}$, J. de-Miguel-Rodríguez ${ }^{1}$, J.M.C. Estêvão ${ }^{2}$ \\ ${ }^{1}$ Department of Building Structures and Geotechnical Engineering, University of Seville, Spain \\ Av. Reina Mercedes, 2, 41012, Seville, Spain \\ \{marisasegovia, ejem, ame, mrequena1, eromero13, jdemiguel\}@us.es \\ ${ }^{2}$ Department of Civil Engineering, ISE, University of Algarve, Faro, Portugal \\ Campus da Penha, 8005-139, Faro, Portugal \\ e-mail: jestevao@ualg.pt
}

\begin{abstract}
A project named PERSISTAH is being developed to study the seismic vulnerability of primary schools in Huelva (Spain) and the Algarve (Portugal). This area has a moderate seismicity but this is affected by a nearby area where earthquakes of large magnitude (Mw $\geq 6)$ and longreturn periods happen.

The seismic vulnerability of URM (UnReinforced Masonry) buildings has been observed and analysed in the last decades. The seismic retrofitting of these buildings is required in order to improve their seismic behaviour. Many retrofitting techniques have been developed for that purpose, most of them very complicated and expensive. Therefore, these are not appropriate to retrofit a large number of buildings. This is especially relevant in areas of moderate seismicity where the cost-efficiency ratio must be carefully considered.

The aim of this paper has been to develop a simple, effective and affordable technique to retrofit these buildings. These buildings are characterised by numerous openings which causes a great weakness in the URM walls. Then, a technique that consists in installing a steel encirclement or a grille in the openings of the walls has been proposed. This is a specific retrofitting technique for URM walls since this technique substantially improves the seismic capacity of these structures.

To test the technique a case study is proposed. The building under study is a primary school located in Huelva and built in 1961. Results have shown that the capacity of the building is notably increased. Also, the performance point and the damage level of the structure are decreased.
\end{abstract}

Keywords: URM buildings, retrofitting technique, Performance-based method, seismic behaviour, nonlinear analysis. 


\section{INTRODUCTION}

The south of the Iberian Peninsula (IP) has a moderate seismicity. This area is close to the borders of the Eurasian and African plates where many active faults exist. Specifically, the southwestern IP is affected by several faults such as the Gibraltar-Azores, the San Vicente Cape and the Horseshoe faults. These faults have originated in the past some important earthquakes like the Lisbon earthquake in $1755(\mathrm{Mw}=8.5)$ and the 1969 earthquake $(\mathrm{Mw}=8)$ [1][2].

The seismic risk in this area is being assessed in a project named PERSISTAH (Projetos de Escolas Resilientes aos SISmos no Território do Algarve e de Huelva, in Portuguese). This project is being developed collaboratively by the University of Algarve and the University of Seville due to the similar seismic hazard of both regions. The aim of this project is to minimize the disaster risk of school buildings in the regions of Andalucia (Spain) and Algarve (Portugal). In the PERSISTAH framework, a total amount of 281 schools will be evaluated in both regions. Most of them were built without any consideration of the seismic actions.

Approximately half of the school building stock have URM structures with load-bearing walls. URM buildings are especially prone to damage due to seismic actions. Its vulnerability has been observed and analysed in the last decades by many authors. Some studies have developed different methods to assess the seismic vulnerability of existing buildings. Usually, methods based on the capacity spectrum are used to characterize the vulnerability and fragility of the buildings [3]. The seismic performance analysis results show the damage level that a building would suffer in case of an earthquake. Moreover, it allows to identify the structural characteristics that reduce the vulnerability of the buildings. In some studies, the damage estimated for a specific structure pertaining to a given typology is considered as representative for the whole group of structures belonging to the aforementioned structural typology [4], as is the aim of the PERSISTAH project. These studies have concluded that a seismic retrofitting of the structure would be required in order to improve their seismic behaviour.

The most common retrofitting strategies used for masonry buildings are (a) reinforcement of connections (wall to wall, wall to floor or wall to roof), (b) transforming flexible floors into rigid diaphragms, (c) improving the out-of-plane behaviour through tied rods or ring beams, and (d) reinforcement of masonry panels. These techniques have been applied in numerous studies and they have resulted effective [5] [6] [7] [8]. The case study building has good connections and rigid floors, which makes the reinforcement of panels the most suitable reinforcement technique to improve its behaviour. The reinforcement of panels has been implemented by means of the addition of diverse materials: reinforced concrete, steel, fibre polymer, polypropylene, mortar renders or injections. These techniques are often complex to perform, non-reversible and expensive. Since the aim of the PERSISTAH project is to retrofit a large number of buildings, these techniques are not the best option.

The school buildings are characterised by numerous openings, which cause a substantial weakness in the URM walls in case of an earthquake. In fact, none of these buildings have been designed considering seismic loads, since they were built prior to any seismic code or with emerging and permissive codes. Therefore, they may not be capable of resisting these actions without being damaged. This work aims to study a simple, effective and inexpensive technique to retrofit these buildings, which consists in installing steel encirclements in the openings of the walls.

A recent paper has experimentally studied this technique by means of cyclically testing an specimen to failure [9]. The authors have concluded that the encirclements led to a significant increase in strength and in-plane deformation capacity, as well as in cumulative dissipated energy at collapse. Comparing a retrofitted wall to a solid masonry wall (without openings), they have stablished that the results were very similar, especially in terms of peak strength. 
To test this reinforcement technique a case study was conducted. The building is a primary school building located in Huelva (Spain) and built in 1961. It is an E-shaped, two storied building, with clay brick URM load-bearing walls and ribbed floor slabs.

A seismic performance-based assessment based on the N2 method was carried out (section 2.2). Then, a damage assessment was performed (section 2.3). Next, six different variants of the reinforcement technique (encirclements) were studied. Three of them consist solely on adding an L-profile to the window border, and the other three include also different types of grilles covering the window surface (section 2.4). The results of the retrofitted building assessment are shown in section 3 and analysed in section 4. Finally, the conclusions are outlined in section 5 .

\section{METHOD}

\subsection{Case study}

The building under study is a two-storied school building located in Huelva (Spain) and built in 1961. The plan has an E-shape with $45 \mathrm{~m}$ by $21 \mathrm{~m}$ as larger dimensions. The building is composed of the intersection of four lineal blocks. One of them is wider, with an entrance gallery, staircases and two classrooms. The other three blocks are narrower, only equipped with classrooms.

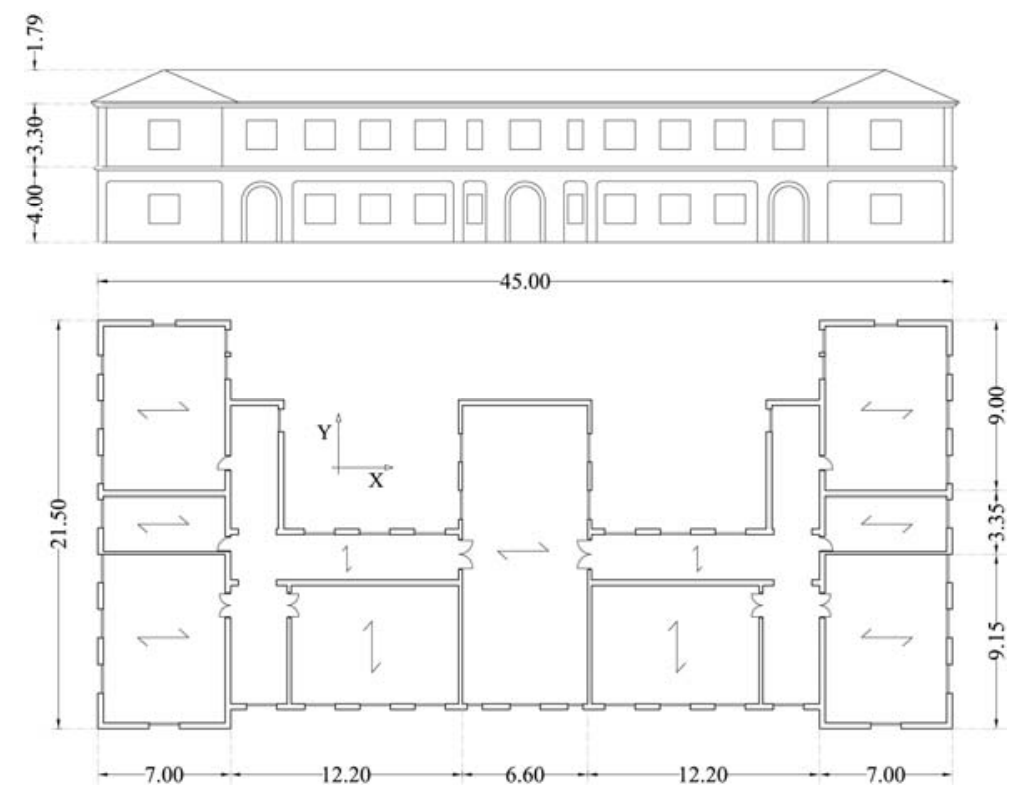

Figure 1: Architectural plans. Base floor (superior). Façade (inferior).

The structural system of the building consists of URM walls of clay brick and cement mortar. The walls have a thickness of $25 \mathrm{~cm}$ and a reinforced concrete ring beam on their top level. The floor structure is made up of ribbed floor slabs $25 \mathrm{~cm}$ thick. The foundation is a concrete beam on strip footings. The building has a sloping roof with tiles.

The load values used in the analysis were obtained from the Spanish building code [10]. For structural analyses, the dead load assigned to the ground and first floor was $5.3 \mathrm{kN} / \mathrm{m}^{2}$ (including floor slabs, pavement and partition walls), and $6.3 \mathrm{kN} / \mathrm{m}^{2}$ to the roof floor (including floor slab, and construction elements of the gable roof). The live load assigned to the school floors was $3 \mathrm{kN} / \mathrm{m}^{2}$ (public use), and $1 \mathrm{kN} / \mathrm{m}^{2}$ in case of the roof floor (maintenance). 
The mechanical properties of masonry elements are typically available in the literature when these pertain to historical buildings. However, the mechanical properties of modern masonry elements are less likely to be found, as is the case of this building.

On one hand, these properties have been calculated using formulations from current codes as Eurocode 6 [11], and UIC Code 778-3 [12]. On the other hand, the data of the mechanical properties of brick clay and mortar have been obtained from project documents of similar construction dates (Table 1).

\begin{tabular}{lc}
\hline Mechanical properties & Value \\
\hline Compressive strength $\left(f_{\mathrm{m}}\right)(\mathrm{MPa})$ & 5 \\
Shear strength $\left(t_{0}\right)(\mathrm{MPa})$ & 0.24 \\
Young's modulus $(E)(\mathrm{MPa})$ & 3,500 \\
Shear modulus $(G)(\mathrm{MPa})$ & 875 \\
Weight density $(W)\left(\mathrm{kN} / \mathrm{m}^{3}\right)$ & 15 \\
\hline
\end{tabular}

Table 1: mechanical properties adopted for the brick masonry walls.

\subsection{Seismic performance-based assessment}

The URM structures have a non-linear behaviour due to their low tensile strength. Consequently, non-linear analyses must be used to evaluate them. [13]. In order to assess the seismic performance of buildings by means of nonlinear static analyses, the European code EC83 [14] recommends the N2 method. This method combines the pushover analysis with the demand spectrum. The displacement capacity of the structure and the seismic demand displacement must be intersected to obtain the performance point, which is the base parameter of the global seismic assessment [15]. The pushover analysis is a static non-linear analysis that consist of applying a horizontal incremental load until the collapse of the structure is reached. The result of this analysis is a capacity curve that represent the base shear with respect to the horizontal displacement of the control node, which is located on the top of the structure.

The masonry wall structure was modelled with the Equivalent Frame Model [16], using the Tremuri software [17]. In this model, the URM walls are divided in macro-elements to form an equivalent frame. The model is composed of piers and spandrel elements assembled through rigid nodes. The formulation used to model the elements is defined from the dissipative mechanism observed in real masonry structures affected by seismic actions. This model considers the possibility of flexural-rocking, shear-sliding and diagonal-cracking shear failure modes, allowing to simulate the non-linear in-plane behaviour of URM walls with acceptable accuracy [18].

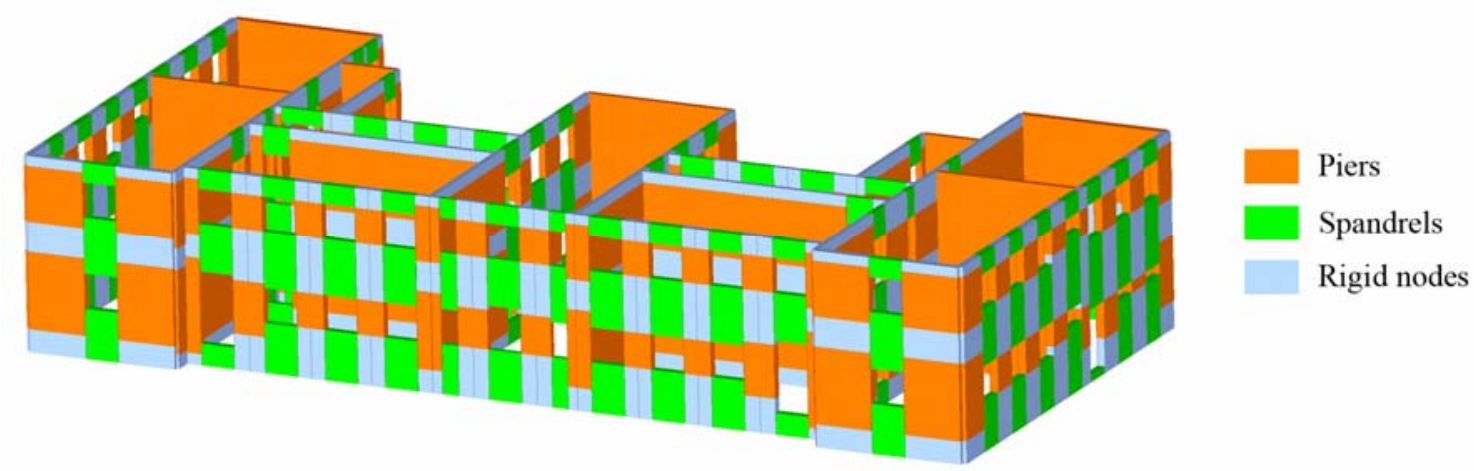

Figure 2: Three-dimensional view of the case study building model in Tremuri. 
The seismic demand is defined in terms of a response spectrum, obtained from the EC81[19] and the Spanish annex [20]. The seismic action in Huelva is defined by the reference peak ground acceleration $(\mathrm{agR})$ whose value is $0.12 \mathrm{~g}$ according to the Spanish update of the seismic hazard maps [21]. Other parameters used to obtain the response spectrum are the importance factor and the soil coefficient. The importance factor depends on the use of the building. School buildings have an importance of class III, so the corresponding importance factor is 1.3. Regarding the soil coefficient, the type of soil has been defined from a geotechnical study performed in a near location. This study established that the soil is composed by a layer of silt-sand with medium-low compactness. According to the dynamic penetration test (DPSH) performed, the type of soil was determined as B, thus the corresponding soil coefficient is 1.2 .

\subsection{Damage assessment}

The seismic performance of the reinforced buildings may be compared in terms of fragility curves. These curves describe the probability of reaching a given state of damage in a defined seismic scenario. The curves are defined by a lognormal function (Eq. 1) that expresses the probability of reaching or exceeding a defined damage state, given the spectral displacement.

$$
P\left\lceil d_{s} \mid S_{d}\right\rceil=\Phi\left[\frac{1}{\beta_{d s}}\right] \ln \left(\frac{S_{d}}{\bar{S}_{d, d s}}\right)
$$

Where $S_{\mathrm{d}}$ is the spectral displacement; $d_{s}$ is the damage state; $\Phi$ is the standard normal cumulative distribution function; $\beta_{\mathrm{ds}}$ is the standard deviation of the natural logarithm of spectral displacement for damage state $d s$; and $\overline{\mathrm{S}}_{\mathrm{d}, \mathrm{ds}}$ is the median value of spectral displacement at which a building reaches the threshold of damage state $d_{s}$.

The damage states considered according to the RISK-EU project (Eq. 2) are: slight damage $\left(S_{\mathrm{d}, 1}\right)$, moderate damage $\left(S_{\mathrm{d}, 2}\right)$, severe damage $\left(S_{\mathrm{d}, 3}\right)$ and complete damage $\left(S_{\mathrm{d}, 4}\right)$. The damage limit states were obtained from the idealised bilinear capacity curves. These states were defined by the yielding and ultimate displacements, as it is proposed in [22].

$$
\begin{aligned}
& \mathrm{S}_{\mathrm{d}, 1}=0.7 \mathrm{~S}_{\mathrm{dy}} \\
& \mathrm{S}_{\mathrm{d}, 2}=1.5 \mathrm{~S}_{\mathrm{dy}} \\
& \mathrm{S}_{\mathrm{d}, 3}=0.5\left(\mathrm{~S}_{\mathrm{dy}}+\mathrm{S}_{\mathrm{du}}\right) \\
& \mathrm{S}_{\mathrm{d}, 4}=\mathrm{S}_{\mathrm{du}}
\end{aligned}
$$

Then, the damage states probabilities were obtained by intersecting the fragility curves and the target displacements. Finally, the damage index (DI) or the mean damage value were calculated to represent the global expected damage in the structure with each reinforcement technique. The DI may be obtained from Eq. 3 [23]:

$$
D I=\sum_{i=0}^{n} i \times P\left(d_{s_{i}}\right)
$$

where $n$ is the number of damage states, and $P\left(d_{\mathrm{si}}\right)$ is the probability that a damage state $i$ occurs. The DI values range between 0 (no structural damage) and 4 (complete damage). 


\subsection{Strengthening technique}

School buildings are usually characterised by numerous openings in the external walls. The presence of openings weakens the building under seismic action. Therefore, the reinforcement strategy chosen consisted in strengthening the openings, installing a steel encirclement in the building windows. A steel profile was fixed in the outer perimeter of the windows, with the possibility of adding a grille covering the whole surface of the window. The doors were not reinforced due to the difficulty of fixing the lower profile under the flooring. In any case, there are not as many doors as windows in these buildings. The advantages of this technique are that it is non-intrusive, easy to install (and remove) and cost-effective.

Six types of reinforcement were tested. The first three types consist on the installation of L-profiles of sizes L100.10, L150.10 and L200.15, respectively, on the windows perimeter (Figure 4a). The last three types are window grilles. Grille 1 includes an L100.10 profile in the perimeter and horizontal tubular profiles of $60 \times 40 \mathrm{~mm}$ covering the windows surface (Figure 4b). Grille 2 combines a perimeter steel plate of $45 \times 5 \mathrm{~mm}$, horizontal $12 \mathrm{~mm}$ bars and two diagonal $12 \mathrm{~mm}$ bars (Figure 4c). Finally, Grille 3 was designed as the combination of a perimeter steel plate of $45 \times 5 \mathrm{~mm}$ and seven diagonals $10 \mathrm{~mm}$ bars in both directions (Figure $4 d)$.

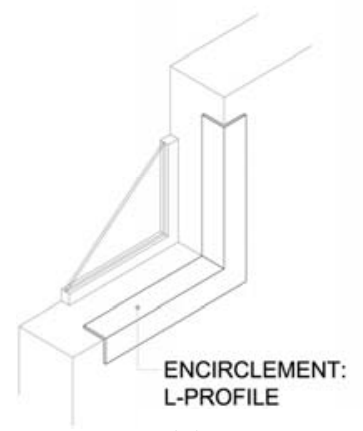

(a)

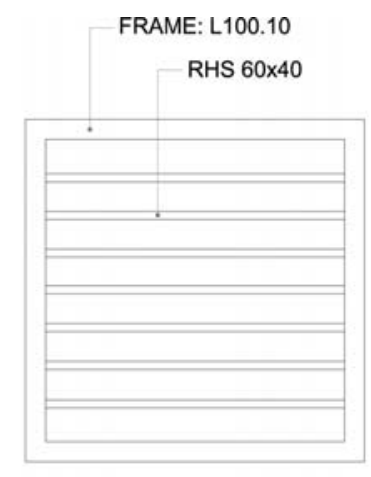

(b)

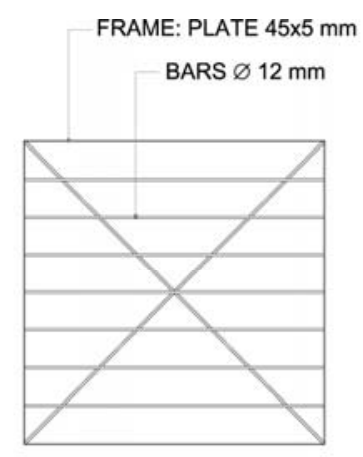

(c)

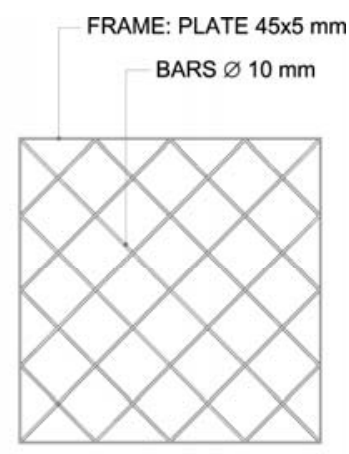

(d)

Figure 4: Reinforcements types: encirclements with L-profile (a), Grille 1 (b), Grille 2 (c) and Grille 3 (d).

The type of steel used in all reinforcements is S275JR steel both for profiles and bars. Their installation includes removing the windowsill, setting the encirclements or grilles (fixed with mechanical anchoring), and placing the windowsill back again. All six types of reinforcements integrate well with the architecture of the building.

The encirclements can be modelled in the Tremuri software, just setting this option in the window definitions. By contrast, the grilles are not included in the reinforcement library, but they can be simulated using an encirclement with equivalent rigidity. This equivalent encirclement was obtained applying a constant horizontal load to the grille and finding a profile which provided the same displacements.

\section{RESULTS}

\subsection{Unretrofitted building}

The results obtained from the seismic performance-based assessment of the unretrofitted building are presented hereafter. To obtain the capacity curves, a pushover analysis was performed in the two main orthogonal directions of the building $(+\mathrm{X},-\mathrm{X},+\mathrm{Y}$ and $-\mathrm{Y})$, considering two lateral load patterns (uniform and triangular). Moreover, the existence or absence of an accidental eccentricity of $5 \%$ of the maximum size of the building (positive or negative) 
was considered. A total of 24 different analyses were carried out and the worst-case combination for each direction was selected.

In Figure 3, it can be observed that the capacity curves in both directions $\mathrm{X}$ and $\mathrm{Y}$ are quite similar in terms of capacity. Regarding the ductility, defined by the ratio between ultimate and yielding displacements, the building presents a larger ductility in the $\mathrm{X}$ direction.

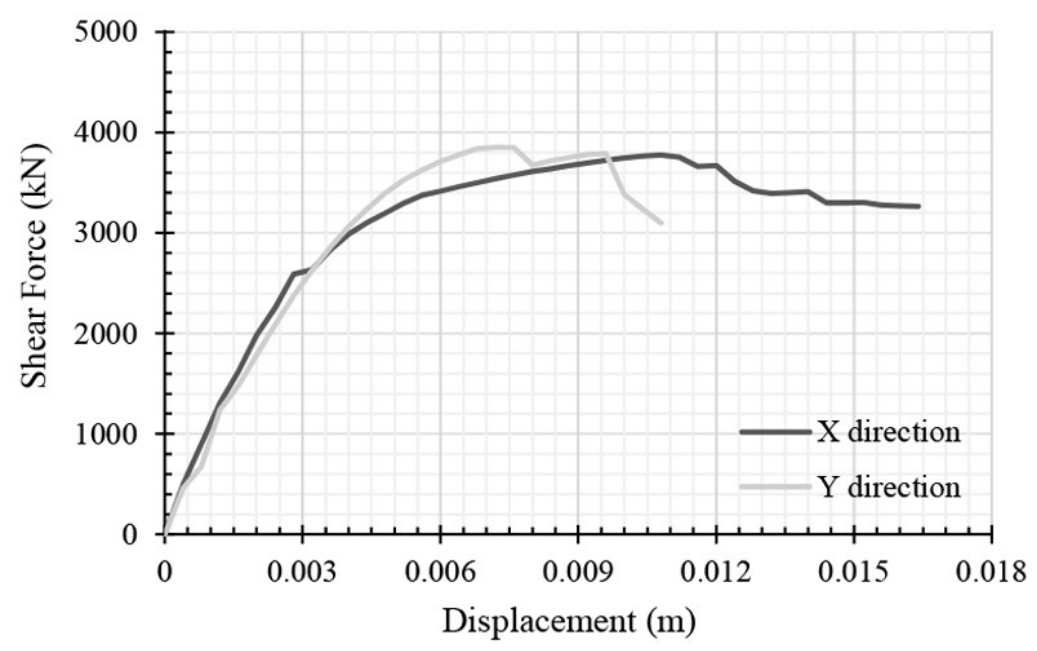

Figure 3: Capacity curves of the reference building in both directions $\mathrm{X}$ and $\mathrm{Y}$.

After that, the performance points were calculated according to the N2 method. The main parameters used in the analysis are defined in the following paragraphs. Their values are summarized in Table 2.

\begin{tabular}{lcccccc}
\hline & $\Gamma$ & $\mathrm{T}^{*}(\mathrm{~s})$ & $\mu$ & $\mathrm{F}_{\mathrm{y}}{ }^{*} / \mathrm{m}^{*}(\mathrm{~g})$ & $\mathrm{q}^{*}$ & $\mathbf{d}_{\mathbf{u}}{ }^{*} / \mathbf{d}_{\mathbf{t}}{ }^{*}$ \\
\hline X direction & 1.20 & 0.24 & 3.34 & 2.47 & 1.72 & $\mathbf{0 . 9 9}$ \\
Y direction & 1.29 & 0.23 & 3.28 & 2.59 & 1.64 & $\mathbf{0 . 7 0}$ \\
\hline
\end{tabular}

Table 2: Parameters and results of the analysis of the reference building.

$\Gamma$ is the transformation factor, required to convert the parameters of the Multi Degree of Freedom (MDOF) system into an equivalent Single Degree of Freedom (SDOF) system and vice versa.

$T^{*}$ is the period of the idealized equivalent SDOF system

$\mu$ is the ductility, the ratio between ultimate and yielding displacements.

$F_{\mathrm{y}}{ }^{*} / \mathrm{m}^{*}$ is the limited structural strength, the ratio between the ultimate strength and the mass of an equivalent SDOF system.

$q^{*}$ is the ratio between the acceleration of the structure with unlimited elastic behaviour $\left(S_{\mathrm{e}}\left(T^{*}\right)\right)$ and the limited structural strength $\left(F_{\mathrm{y}}{ }^{*} / m^{*}\right)$.

The results of the analysis, in terms of the ratio between ultimate displacement $\left(d_{\mathrm{u}}{ }^{*}\right)$ and target displacement in the equivalent SDOF system $\left(d_{\mathrm{t}}{ }^{*}\right)$ are also shown in table 2.

The ultimate limit state (ULS) safety verification according to the EC8-3 consist in checking that the ratio $\mathrm{d}_{\mathrm{u}}{ }^{*} / \mathrm{d}_{\mathrm{t}}{ }^{*}$ is higher than 1 . It can be observed that this condition is not satisfied either in $\mathrm{X}$ or $\mathrm{Y}$ direction, although the results in $\mathrm{Y}$ are significantly worse. Non-compliance of the safety conditions indicated that the building required to be retrofitted. 


\subsection{Retrofitted building}

Figure 5 shows the results of the pushover analysis in terms of capacity curves in $\mathrm{X}$ and $\mathrm{Y}$ directions for the retrofitted building (with all six types of reinforcements) and the unretrofitted building (reference building).
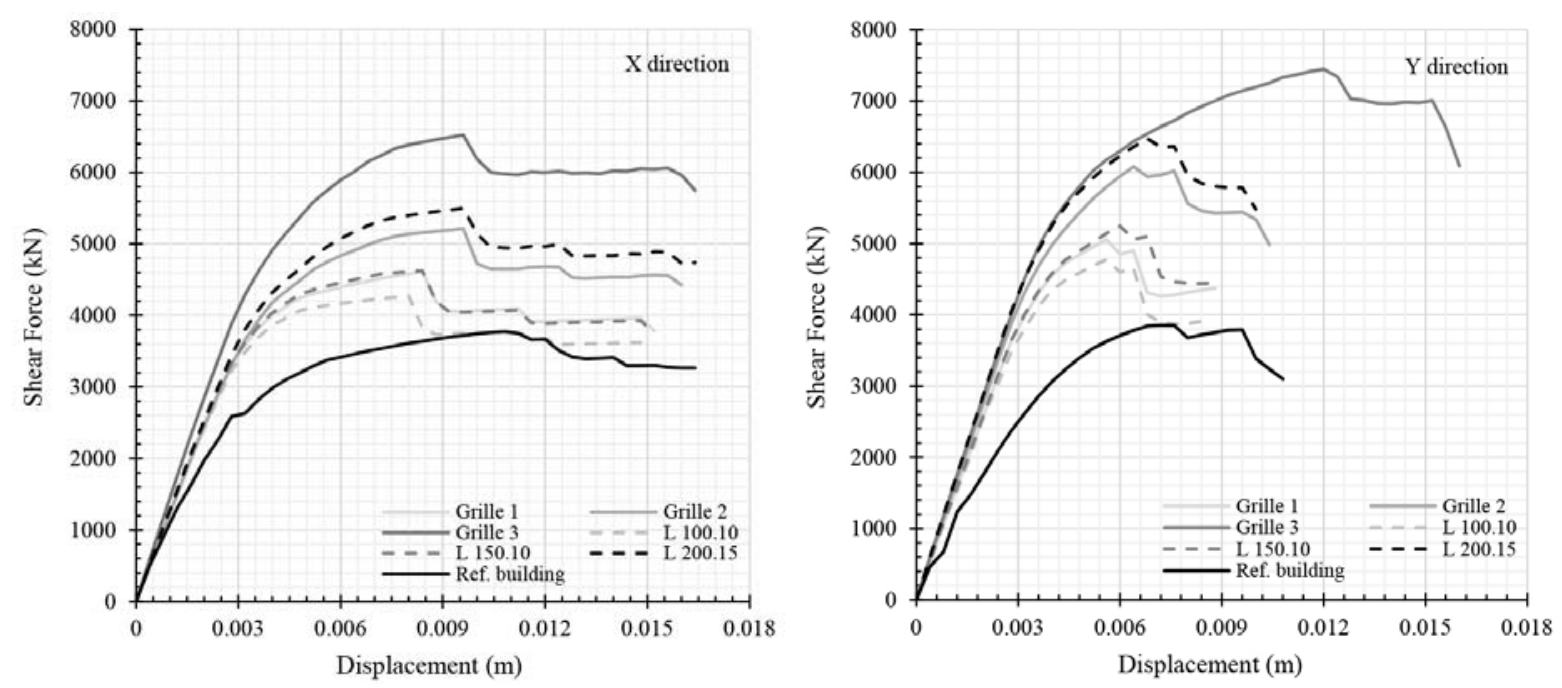

Figure 5: Capacity curves for each reinforcement technique, $\mathrm{X}$ direction (left) and $\mathrm{Y}$ direction (right).

As mentioned in the previous section, the performance points were obtained intersecting the capacity curves and the seismic displacement demand, as established in the N2 method. In Figure 6, the performance points of the reference and the reinforced buildings are shown.
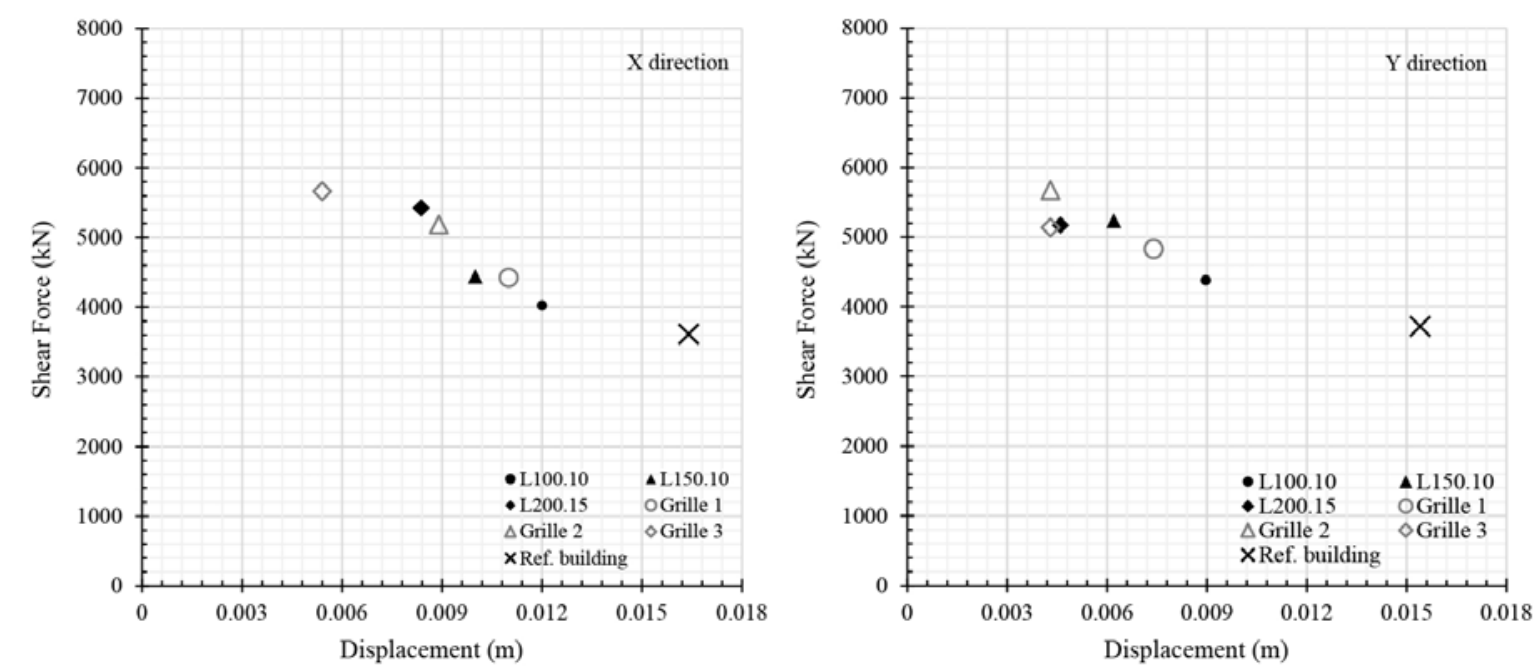

Figure 6: Performance point for each reinforcement technique in $\mathrm{X}$ (left) and Y direction (right).

In Table 3, the results of the N2 method are summarized. They are the target displacements (dt), obtained for the elastic response spectra defined in EC8-1; the yielding (dy) and ultimate (du) displacements. The ductility $(\mu)$ of each reinforcement type was calculated as the ratio $d_{\mathrm{u}}{ }^{*} / d_{\mathrm{y}}{ }^{*}$. Finally, the ratio $d_{\mathrm{u}}{ }^{*} / d_{\mathrm{t}}{ }^{*}$, that allowed to verify the ULS safety according to the EC8-3 was obtained. 
María-Luisa Segovia-Verjel, Enrique Justo-Moscardó, Antonio Morales-Esteban, María-Victoria RequenaGarcía-Cruz, Emilio Romero-Sánchez, Jaime de Miguel-Rodríguez, João M.C. Estêvão

\begin{tabular}{llccccc}
\hline & & $\mathrm{d}_{\mathrm{t}}{ }^{*}$ & $\mathrm{~d}_{\mathrm{y}}{ }^{*}$ & $\mathrm{~d}_{\mathrm{u}}{ }^{*}$ & $\mu$ & $\mathbf{d}_{\mathbf{u}}{ }^{*} / \mathbf{d}_{\mathbf{t}}{ }^{*}$ \\
\hline X direction & Ref. building & 1.37 & 0.40 & 1.36 & 3.40 & $\mathbf{0 . 9 9}$ \\
& L100.10 & 1.00 & 0.31 & 1.23 & 3.97 & 1.23 \\
& L150.10 & 0.90 & 0.34 & 1.26 & 3.71 & 1.40 \\
& L200.15 & 0.69 & 0.41 & 1.35 & 3.29 & 1.96 \\
& Grille 1 & 0.92 & 0.35 & 1.26 & 3.60 & 1.37 \\
& Grille 2 & 0.76 & 0.42 & 1.32 & 3.14 & 1.74 \\
& Grille 3 & 0.44 & 0.35 & 1.34 & 3.83 & 3.05 \\
& Ref. building & 1.19 & 0.36 & 0.83 & 2.31 & $\mathbf{0 . 7 0}$ \\
& L100.10 & 0.69 & 0.28 & 0.65 & 2.32 & $\mathbf{0 . 9 4}$ \\
& L150.10 & 0.48 & 0.33 & 0.67 & 2.03 & 1.40 \\
& L200.15 & 0.34 & 0.30 & 0.75 & 2.50 & 2.21 \\
& Grille 1 & 0.57 & 0.30 & 0.67 & 2.23 & 1.18 \\
& Grille 2 & 0.32 & 0.28 & 0.79 & 2.82 & 2.47 \\
& Grille 3 & 0.32 & 0.29 & 1.20 & 4.14 & 3.75 \\
\hline
\end{tabular}

Table 3: Results obtained for each reinforced building through the N2 method (displacements in $\mathrm{cm}$ ).

The fragility curves were derived from the capacity curves. Intersecting the fragility curves with the target displacements allowed to determine the damage states probabilities (table 4). Finally, the DI for each reinforcement condition was calculated. The results are shown in Figure 7.

\begin{tabular}{llccccc}
\hline & & $\begin{array}{c}0 \\
\text { No } \\
\text { damage }\end{array}$ & $\begin{array}{c}\text { Slight } \\
\text { damage }\end{array}$ & $\begin{array}{c}2 \\
\text { Moderate } \\
\text { damage }\end{array}$ & $\begin{array}{c}3 \\
\text { Severe } \\
\text { damage }\end{array}$ & $\begin{array}{c}4 \\
\text { Complete } \\
\text { damage }\end{array}$ \\
\hline X direction & Ref. building & 0 & 0.29 & 9.88 & 39.56 & 50.25 \\
& L100.10 & 0 & 0.53 & 15.37 & 45.77 & 38.31 \\
& L150.10 & 0 & 1.65 & 21.68 & 45.31 & 31.37 \\
& L200.15 & 0.2 & 15.3 & 34.18 & 33.91 & 16.37 \\
& Grille 1 & 0 & 1.65 & 21.07 & 44.87 & 32.43 \\
& Grille 2 & 0.04 & 9.26 & 31.37 & 38.05 & 21.26 \\
& Grille 3 & 12.97 & 41.38 & 23.64 & 16.02 & 5.96 \\
Y direction & Ref. building & 0 & 0.34 & 5.83 & 24.8 & 69.01 \\
& L100.10 & 0 & 2.391 & 13.32 & 29.74 & 54.01 \\
& L150.10 & 0.32 & 17.48 & 20.91 & 27.9 & 33.37 \\
& L200.15 & 13.48 & 41.49 & 13.84 & 13.48 & 14.68 \\
& Grille 1 & 0.12 & 12.97 & 21.38 & 30.31 & 35.2 \\
& Grille 2 & 18.38 & 41.73 & 13.55 & 15.09 & 11.23 \\
& Grille 3 & 49.4 & 30.25 & 7.82 & 8.24 & 4.27 \\
\hline
\end{tabular}

Table 4: Damage states probabilities for each retrofitting technique. 


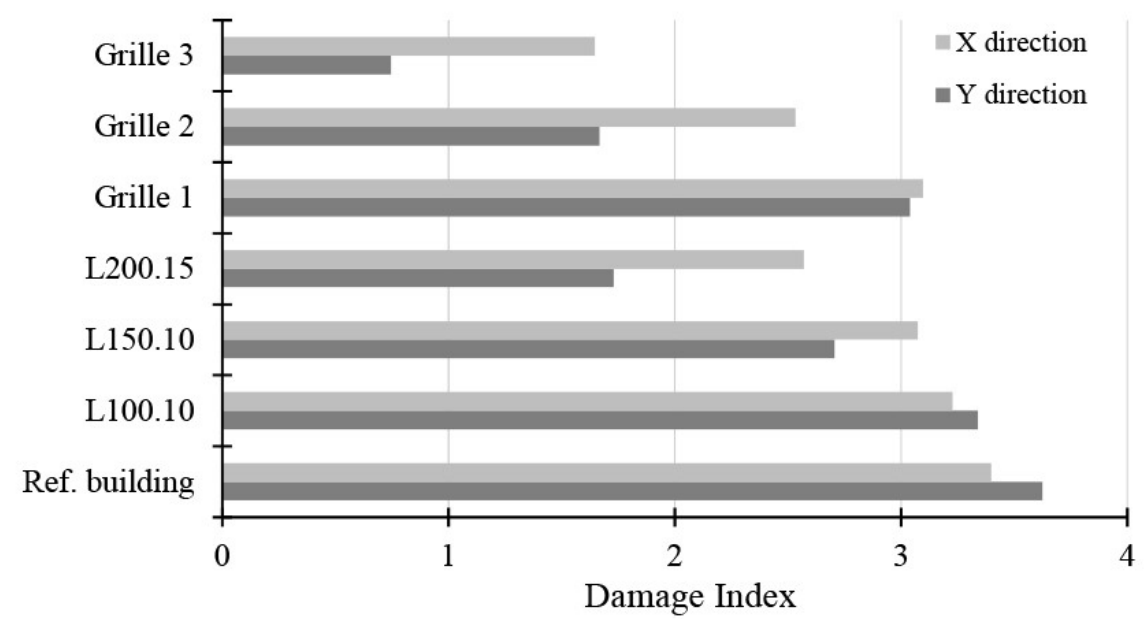

Figure 7: Damage index for the reference building and with each retrofitting technique.

\section{ANALYSIS OF RESULTS}

The results in terms of capacity curves show that both the encirclements alone and the window grilles were effective in both $\mathrm{X}$ and $\mathrm{Y}$ directions. Observing the curves, it can be noticed that all reinforcements provide a noticeable increase in both strength and rigidity.

For the unretrofitted condition, the building capacity was similar in $\mathrm{X}$ and $\mathrm{Y}$ directions, although in $\mathrm{X}$ the ultimate displacement of the structure was higher, indicating higher ductility in X. This may be due to the fact that the piers in the X direction walls are slenderer than those in the $\mathrm{Y}$ direction walls. Slenderer piers lead to a predominant flexural response, with higher values of drift. Otherwise, thick piers (predominant in the Y direction) tend to produce shear failure and lower values of drift. The same results were obtained experimentally in [24] and similar conclusions were reported in [6].

Even though all retrofitting techniques improve capacity, the enhancement is greater in $\mathrm{Y}$ than in $X$ in all cases. In $X$ direction, the maximum shear force increased between $11 \%$ (L100.10 encirclements) and 57\% (Grille 3). In Y direction, the enhancement ranged between $24 \%$ (profile L100.10) and almost 100\%, in the case of Grille 3.

Figure 6 shows the performance point of the reference building and the six reinforcement cases. In all cases, in line with their capacity improvement, the reinforced buildings presented a great decrease of the displacements as compared to the reference building. This reduction was from $25 \%$ to $69 \%$ along the $\mathrm{X}$ axis, and from $38 \%$ to $69 \%$ along the $\mathrm{Y}$ axis.

Table 3 presents the results of the N2 analysis in terms of the target $d_{\mathrm{t}}{ }^{*}$, ultimate $d_{\mathrm{u}}{ }^{*}$ and yielding displacements $d_{\mathrm{y}}{ }^{*}$. Observing the ductility values, it can be noted that in most cases the retrofitting produced only a slight improvement in both directions. Even in some cases (e.g., L150.10 in Y), the ductility decreased when the reinforcement was applied. In general, the building presented a less ductile behaviour in the $\mathrm{Y}$ direction, but here once again the Grille 3 reinforcement proved very effective, producing an increase of $80 \%$ in ductility over the reference building. Regarding the ULS safety verification, it can be checked that every retrofitting case except L100.10 (Y direction) satisfied the condition $d_{\mathrm{u}}{ }^{*} / d_{\mathrm{t}}{ }^{*}>1$. The improvement ranged from 38 to $76 \%$ in the $\mathrm{X}$ direction. In the $\mathrm{Y}$ direction, the gain was in most cases up to $100 \%$ or $200 \%$. A $400 \%$ was even reached in case of the Grille 3 .

In Figure 7, the DI for the different reinforcement techniques can be compared. On one hand, it can be observed that adding the L100.10 encirclement produced a minimal decrease of DI in both axis and did not changed significantly the building's behaviour. Adding Grille 1 produced a slight improvement in behaviour with a small reduction of the DI, down to severe 
damage. On the other hand, the addition of L150.10 profiles provided a significant reduction of damage in Y direction, although the gain was minimal in X direction. Furthermore, applying the L200.15 encirclement or the Grille 2 led to significant improvements in both directions, especially in Y, where the DI was reduced below to moderate damage. Finally, the Grille 3 is the reinforcement that produced the best results. In this last case, the DI was reduced below moderate damage in the $\mathrm{X}$ direction and below slight damage in the $\mathrm{Y}$ direction.

In terms of DI, the behaviour of the unretrofitted building was slightly better in the $\mathrm{X}$ direction. Nevertheless, all reinforcements provided higher enhancements in the Y direction with the exception of the L100.10 case. This can be explained observing the building geometry. Firstly, there is symmetry in the plan building in the $\mathrm{Y}$ axis but not in the $\mathrm{X}$ axis. Moreover, despite the fact that there are similar number of openings in both directions, they are distributed uniformly in the Y direction, but not in the $\mathrm{X}$ direction, which increase the lack of symmetry in this direction. Thus, the vulnerability in the Y direction is mainly caused by the presence of openings in the walls, and can be substantially reduced with these retrofitting techniques. On the contrary, in the $\mathrm{X}$ direction, the vulnerability of the building is produced by many factors, including lack of symmetry and the irregular distribution of openings. As a consequence, the reinforcement of openings in the $\mathrm{X}$ walls is not as much effective as in the $\mathrm{Y}$ walls.

\section{CONCLUSIONS}

This work is framed in the PERSISTAH project, which aims to analyse the seismic vulnerability of primary school buildings located in the region Algarve-Huelva. In the present paper, the seismic vulnerability of a URM primary school building located in Huelva was assessed. The main goal was to develop a simple, effective and affordable technique to retrofit a large number of buildings. The seismic performance of the building with different retrofitting techniques was assessed using the N2 method, as recommended by the EC8-3. Nonlinear static analyses were performed to obtain the capacity curves of the building including the retrofitting techniques. Moreover, the fragility curves were determined to obtain the probability of reaching or exceeding each damage state. Finally, the DI for each retrofitting technique model was obtained and compared.

The results showed that the unretrofitted building presented a high seismic vulnerability and did not satisfy the EC8-3 ULS verification. Therefore, to avoid future damage in the event of an earthquake, a retrofitting technique based on reinforcing the wall openings was proposed. Six different reinforcement scenarios were tested, three of them with encirclements and the other three with grilles. The results showed that the seismic behaviour of the building improved considerably when the reinforcements were applied. In particular, a noticeable increase in capacity and an important decrease in the performance point values were observed. Regarding the EC8 ULS safety verification, the results showed that all retrofitting techniques have been effective, except in the case of the encirclement with L100.10 profile.

In terms of damage level reduction, it can be concluded that, in general, all reinforcement techniques improved the seismic behaviour of the building. On one hand, the encirclements led to enhance the seismic performance of the building, provided that the profile size is appropriate. As for the grilles, the results have shown that adding grilles composed by horizontal tubular profiles did not enhance significantly the damage level of the structure. On the contrary, including the diagonal bars has proved much more effective. Furthermore, it was found that a higher number of diagonal bars produced a higher improvement in the damage level. Consequently, the Grille 3 reinforcement, in which all bars are placed in a diagonal pattern, resulted the most suitable design. In this case, the architectural integration is better due to the use of a plate in the perimeter, instead of an L-profile. Moreover, the reinforcement of Grille 3 
has the best cost-benefit ratio since the plates and bars included require less steel than the encirclements with L profiles. Furthermore, this has resulted to be the most optimal and efficient retrofitting technique to improve the seismic behaviour of the URM primary school buildings studied in Huelva and the Algarve.

\section{ACKNOWLEDGEMENTS}

This work has been supported by the INTERREG-POCTEP Spain-Portugal programme and the European Regional Development Fund through the 0313_PERSISTAH_5_P project.

\section{REFERENCES}

[1] D.K. Chester., O.K. Chester. The impact of eighteenth century earthquakes on the Algarve region, southern Portugal. Geographical Journal, 176, 350-70, 2010.

[2] R. Bartolome., E. Gràcia., D. Stich., S. Martínez-Loriente., D. Klaeschen., F. de Lis Mancilla., C. Lo Iacono., J.J. Dañobeitia., N. Zitellini. Evidence for active strike-slip faulting along the Eurasia-Africa convergence zone: Implications for seismic hazard in the southwest Iberian margin. Geology, 40, 495-8, 2012.

[3] A.H. Barbat., L.G. Pujades., N. Lantada. Performance of buildings under earthquakes in Barcelona, Spain. Computer-Aided Civil and Infrastructure Engineering, 21, 573-93, 2006.

[4] A.H. Barbat., S. Lagomarsino., L.G. Pujades. Vulnerability assessment of dwelling buildings. In Assessing and managing earthquake risk, eds., C. S. Oliveira, A. Roca, and X. Goula. Dordrecht, The Netherlands: Springer, 115-134, 2006.

[5] R. Maio., J.M.C. Estêvão., T.M. Ferreira., R. Vicente. The seismic performance of stone masonry buildings in Faial island and the relevance of implementing effective seismic strengthening policies. Engineering Structures, 141, 41-58, 2017.

[6] H.A. Meireles., R. Bento. Seismic assessment and retrofitting of Pombalino buildings by fragility curves. 15th World Conference on Earthquake Engineering, Lisbon Portugal, 1-10, 2012.

[7] J. Ortega., G. Vasconcelos., H. Rodrigues., M. Correia. Assessment of the efficiency of traditional earthquake resistant techniques for vernacular architecture. Engineering Structures, 173, 1-27, 2018.

[8] S. Diz., A. Costa., A.A. Costa. Efficiency of strengthening techniques assessed for existing masonry buildings. Engineering Structures, 101, 205-15, 2015.

[9] J.M. Proença., A.S. Gago., A. Vilas Boas. Structural window frame for in-plane seismic strengthening of masonry wall buildings. International Journal of Architectural Heritage, 13, 98-113, 2019.

[10] Gobierno de España. DB SE- AE Seguridad Estructural, Acciones en la Edificación. Boletín Oficial del Estado, 1-42, 2009.

[11] European Union. Eurocode-6: Design of masonry structures. Part 1-1: General rules for reinforced and unreinforced masonry structures, Brussels, 2005. 
María-Luisa Segovia-Verjel, Enrique Justo-Moscardó, Antonio Morales-Esteban, María-Victoria RequenaGarcía-Cruz, Emilio Romero-Sánchez, Jaime de Miguel-Rodríguez, João M.C. Estêvão

[12] Recommandations pour l'Evaluation de la Capacite Portante des Ponts-Voutes Existants en Maconnerie et Beton. Paris: Union Internationales des Chemins de Fer., France, 1995.

[13] S. Lagomarsino., S. Cattari. Seismic Performance of Historical Masonry Structures Through Pushover and Nonlinear Dynamic Analyses. Perspectives on European Earthquake Engineering and Seismology. Vol. 39. pp.265-92 (2015).

[14] European Union. Eurocode-8: Design of structures for earthquake resistance. Part 3: Assessment and retrofitting of buildings, Brussels, 2005.

[15] P. Fajfar., P. Gašperšič. The N2 method for the seismic damage analysis of RC buildings. Earthquake Engineering \& Structural Dynamics, 25, 31-46, 1996.

[16] A. Penna., S. Lagomarsino., A. Galasco. A nonlinear macroelement model for the seismic analysis of masonry buildings. Earthquake Engineering \& Structural Dynamics, 43, 159-79, 2014.

[17] A. Galasco., S. Lagomarsino., A. Penna. TREMURI Program: Seismic Analyser of 3D Masonry Buildings. University of Genoa, 2002.

[18] S. Lagomarsino., A. Penna., A. Galasco., S. Cattari. TREMURI program: An equivalent frame model for the nonlinear seismic analysis of masonry buildings. 2013.

[19] European Union. Eurocode 8: Design of structures for earthquake resistance. Part 1: General rules, seismic actions and rules for buildings, Brussels, 2004.

[20] Spanish Ministry of Public Works [Ministerio de Fomento de España]. Spanish annex to Eurocode-8 [Anexo español al Eurocódigo 8], Madrid, 1998.

[21] Spanish Ministry of Public Works [Ministerio de Fomento de España]. Update of the seismic hazard maps [Actualización de mapas de peligrosidad sísmica de España], Spain, 2012.

[22] S. Lagomarsino., S. Giovinazzi. Macroseismic and mechanical models for the vulnerability and damage assessment of current buildings. Bulletin of Earthquake Engineering, 4, 415-43, 2006.

[23] R. Gonzalez-Drigo., A. Avila-Haro., A.H. Barbat., L.G. Pujades., Y.F. Vargas., S. Lagomarsino., S. Cattari. Modernist unreinforced masonry (URM) buildings of barcelona: Seismic vulnerability and risk assessment. International Journal of Architectural Heritage, 9, 214-30, 2015.

[24] A. Penna., S. Lagomarsino., A. Galasco. A nonlinear macroelement model for the seismic analysis of masonry buildings. Earthquake Engineering \& Structural Dynamics, 43, 159-79, 2014. 